\title{
Redemocratização e direitos humanos: a política para refugiados no Brasil
}

Re-democratization and human rights: refugee policy in Brazil

JULIA BERTINO MOREIRA*

Rev. Bras. Polít. Int. 53 (1): 111-129 [2010]

\section{Introdução: o tema dos refugiados}

Os refugiados constituem um grupo específico dentro das migrações internacionais. Forçados a fugir de seus países de origem em decorrência de conflitos intra ou interestatais, por motivos étnicos, religiosos, políticos, regimes repressivos e outras situações de violência e violações de direitos humanos, essas pessoas cruzam as fronteiras em busca da proteção de outro Estado, com o objetivo primordial de resguardar suas vidas, liberdades e seguranças.

Hoje, existem 15,2 milhões de refugiados no mundo, segundo estimativas das agências da Organização das Nações Unidas (ONU) dedicadas ao grupo: o Alto Comissariado das Nações Unidas para os Refugiados (ACNUR); e a United Nations Relief and Works Agency for Palestinians Refugees (UNRWA), que atua especificamente em prol dos refugiados palestinos, na Faixa de Gaza, Cisjordânia, Jordânia, Síria e no Líbano (ACNUR, 2009; UNRWA, 2009).

Os fluxos atuais, desencadeados por conflitos que se destacam no cenário internacional, assumem uma dinâmica que se direciona claramente no sentido SulSul, com $80 \%$ da população refugiada concentrada no mundo em desenvolvimento. Dentre os países de onde mais se originam refugiados, lideram a Palestina (4,7 milhões), o Afeganistão (2,8 milhōes) e o Iraque (1,9 milhão). Por sua vez, os maiores países acolhedores são: Paquistão (1,8 milhão), Síria (1,1 milhão), Irã (980 mil), Alemanha $(582 \mathrm{mil})$ e Jordânia $(500 \mathrm{mil})$. Apenas dois países desenvolvidos (além da Alemanha, o Reino Unido, com 292 mil) despontam entre os que mais recebem refugiados. Na América Latina, a Colômbia se destaca, com mais de 3 milhões de pessoas deslocadas (ACNUR, 2009; UNRWA, 2009).

A questão dos refugiados acarreta implicações nas relações internacionais, pelo número significativo de pessoas deslocadas, pelos motivos que levam à migração, pela dinâmica dos fluxos, gerando um problema para os países de origem

\footnotetext{
* Doutoranda em Ciência Política pela Universidade de Campinas - Unicamp e pesquisadora do Centro de Estudos de Cultura Contemporânea, CEDEC (juliabertinobr@yahoo.com.br).
} 
e de acolhimento, muitas vezes vizinhos ou da mesma região. As organizações internacionais, em especial o ACNUR, ao lado de ONGs que fornecem ajuda humanitária, tentam influenciar os Estados para acolher essas pessoas que precisam urgentemente de proteção.

Contudo, a decisão de receber refugiados se insere na lógica da soberania estatal, que leva em conta inúmeros fatores externos e internos, como considerações de segurança, capacidade sócio-econômica de absorção, tradição humanitária e respeito a regimes internacionais (Meyers, 2000; Hollifield, 2000; Jacobsen, 1996). É importante ressaltar que a política nacional para refugiados possui um duplo caráter, combinando elementos de política externa com política doméstica, como veremos ao longo do texto.

\section{Refugiados: regimes e políticas}

O tema dos refugiados ganhou destaque no contexto internacional sobretudo após a Segunda Guerra Mundial (1939-45), quando mais de 40 milhões de pessoas se deslocaram no interior da Europa por ocasiáo da guerra. No mesmo momento, a questão dos direitos humanos passou a ser debatida pela comunidade internacional diante das atrocidades cometidas por regimes totalitários. Isso levou à constituição do regime internacional de direitos humanos no âmbito da ONU, com a Declaração Universal de 1948, que previa o direito de procurar e gozar asilo a toda pessoa vítima de perseguição. Poucos anos depois, se fez acompanhar pelo regime internacional para refugiados. (ACNUR, 2000).

$\mathrm{Na}$ esfera institucional, em 1951, criou-se uma agência especializada para proteger os refugiados e encontrar soluçōes para eles: o ACNUR. Ainda foi celebrada a Convenção Relativa ao Estatuto dos Refugiados, que definiu como refugiado aquele

que, em conseqüência dos acontecimentos ocorridos antes de $1^{\circ}$ de janeiro de 1951, e receando com razão ser perseguida em virtude da sua raça, religião, nacionalidade, filiação em certo grupo social ou das suas opiniōes políticas, se encontre fora do país de que tem a nacionalidade e não possa ou, em virtude daquele receio, não queira pedir a proteção daquele país; ou que, se não tiver nacionalidade e estiver fora do país no qual tinha a sua residência habitual após aqueles acontecimentos, não possa ou, em virtude do dito receio, a ele não queira voltar (ACNUR: 1996, 61).

Caberia ao Estado-parte estipular o entendimento adotado sobre a expressão "acontecimentos ocorridos antes de $1^{\circ}$ de janeiro de 1951" (chamada de "reserva temporal"), que poderia ser interpretada como os que tiveram lugar apenas na Europa (conhecida como "reserva geográfica") ou em qualquer lugar do mundo. O Estado que tivesse adotado a primeira fórmula (mais restritiva) poderia, a qualquer momento, mediante comunicação ao Secretário-Geral da ONU, adotar 
a segunda, que contemplava um grupo maior de pessoas na definição de refugiado (ACNUR, 1996).

Assentada em duas limitaçôes, o que evidenciava o tratamento da questão dos refugiados como algo restrito ao continente europeu e gerado pela guerra, a definição "clássica" nascia fadada à inaplicabilidade. Com o início da Guerra Fria, o termo refugiado praticamente se limitava aos europeus de leste que fugiam dos países socialistas, atendendo aos interesses político-ideológicos e geo-estratégicos dos países ocidentais, que buscavam desacreditar o bloco soviético. Também havia interesses econômicos, já que a Europa estava em fase de reconstrução e se fazia necessária mão de obra barata e abundante. Além disso, não havia diferenças culturais, já que se tratava de europeus sendo acolhidos em outros países do continente ou em ex-colônias (Conley, 1993; Matas, 1993).

O regime internacional para refugiados se estruturou a partir do princípio da não-devolução, previsto no artigo 33 da Convenção de 1951, que proibia os Estados signatários de expulsar o refugiado para "as fronteiras dos territórios em que a sua vida ou a sua liberdade seja ameaçada em virtude da sua raça, da sua religião, da sua nacionalidade, do grupo social a que pertence ou das suas opinióes políticas" (ACNUR: 1996, 74). Portanto, estabelecia-se o dever dos países apenas de não devolver, deixando-se de lado a obrigação de receber refugiados, reforçando-se a lógica da soberania estatal.

Os novos fluxos ocorridos na década de 1960, em função da descolonização afro-asiática, geravam uma nova disputa global em torno de zonas de influência pelos dois grandes blocos. Como a questão dos refugiados passou a fazer parte da política externa estadunidense e de outros países ocidentais, percebeu-se a necessidade de se alterar o texto da Convenção. Dessa forma, em 1967, elaborouse o Protocolo sobre o Estatuto dos Refugiados, que pôs fim à chamada reserva temporal da Convenção e impedia os novos países signatários de adotar a reserva geográfica, modificando o regime internacional para refugiados (ACNUR, 1996).

No cenário latino-americano, a experiência regional de conflitos armados por motivos políticos, nos anos 1970 e 1980, levou os países da região a adotar uma nova definição de refugiado, mais compatível com a situação por eles vivenciada. A Declaração de Cartagena de 1984 ampliou a definição do regime internacional da ONU, ao incluir pessoas que deixaram seus países porque sua vida, segurança ou liberdade foram ameaçadas em decorrência da violência generalizada, agressão estrangeira, conflitos internos, violação massiva dos direitos humanos ou outras circunstâncias que perturbaram gravemente a ordem pública (Declaração de Cartagena, 2001).

Ainda nos anos 1980, a conjuntura global se marcou pela recessão econômica internacional provocada pela crise de petróleo ocorrida na década anterior. $\mathrm{O}$ fim da confrontação bipolar teve um impacto significativo nesse contexto, já que não havia mais vantagens e interesses políticos, ideológicos e estratégicos em acolher refugiados provenientes do sul ou mesmo do leste europeu. Somava-se à ausência de 
interesses econômicos, o choque cultural entre os refugiados africanos, asiáticos e latinos que chegavam em peso e as sociedades acolhedoras ocidentais. Esses fatores conjugados levaram o mundo desenvolvido a fechar suas fronteiras aos migrantes em geral, atingindo potenciais refugiados. Em função disso, observou-se uma crise no instituto do refúgio, questionando-se a efetividade do regime internacional delineado pela ONU (Loescher, 1999).

Além disso, os anos 1990 compreenderam um período de construção de uma nova ordem internacional, enfocando-se a interdependência, busca de cooperação, o multilateralismo nas relaçôes internacionais e a emergência de novos temas globais. Dentre eles, destacamos os direitos humanos, discutido na conferência internacional promovida pela ONU em Viena em 1993, ao qual foi atrelado o tema das migrações internacionais, especialmente as forçadas. A Declaração e o Programa de Ação de Viena estipulavam a necessidade de se criar estratégias para combater as causas dos problemas dos refugiados e deslocados, sobretudo os conflitos armados e as violações massivas de direitos humanos. Naquele momento, ressaltava-se a crise global de refugiados, que demandava solidariedade e cooperação internacionais, a partir da repartição de encargos entre países envolvidos nos fluxos e organizaçôes atuantes em prol dos refugiados (Trindade, 1994; Alves, 2003).

\section{Direitos humanos e refugiados: a política brasileira}

A delegação brasileira na Conferência Internacional sobre Direitos Humanos em Viena teve participação de destaque, ocupando o comitê de redação "com reconhecida eficiência”, nas palavras de Trindade (1994). Segundo Alves (2003), essa tarefa representou um voto de confiança na diplomacia brasileira, por sua transparência e retorno ao regime democrático.

O principal ponto da Declaração de Viena se centrou na interdependência entre direitos humanos, desenvolvimento e democracia. Essa posição foi sustentada pelo Brasil, passando a tratar os três temas indissociavelmente (Alves, 2003; Trindade, 1994). Para um país que havia passado por um longo ciclo de autoritarismo, as novas instituiçōes democráticas deveriam vir acompanhadas de um compromisso com o respeito a direitos que haviam sido sistematicamente violados nas décadas anteriores (sobretudo os direitos civis e políticos). Além disso, o país também enfrentava sérias dificuldades financeiras no contexto latinoamericano de endividamento externo. Portanto, para concretizar direitos humanos (aqui, especialmente os direitos econômicos e sociais), era preciso obter fundos para investir no desenvolvimento nacional.

\section{Redemocratização: a retomada do compromisso}

A partir do processo de transição para a democracia, nota-se uma mudança fundamental no tratamento dado ao tema dos direitos humanos no país. Ao longo 
do pós-guerra, o Brasil teve participação ativa na fase de elaboração dos instrumentos internacionais em matéria de direitos humanos no âmbito da ONU, inclusive apresentando propostas (por exemplo, de um texto para a Convenção Americana). No entanto, a partir dos anos 1970, houve um recuo na atuação brasileira em prol dos direitos humanos, em função do autoritarismo no plano interno. Após denúncias de violaçốes de direitos humanos pelo regime militar, o Brasil foi eleito membro da Comissão de Direitos Humanos da ONU em 1977, adotando uma postura "resistente e considerada reativa", segundo Trindade (1994). A ruptura viria com a redemocratização, quando o país passou a se posicionar de forma "transparente, construtiva e cooperativa", nas palavras de Alves (2003), o que marcou a retomada do compromisso com o tema dos direitos humanos iniciada no pós-guerra.

Naquele momento, a política externa brasileira do governo Sarney (1985-89) inovou ao contemplar os direitos humanos, especialmente, ao aderir ao regime internacional desenhado pela ONU. Foi emblemática a decisão de ratificar os dois pactos internacionais (de direitos civis e políticos e de direitos econômicos, sociais e culturais), bem como a convenção contra a tortura (o que só foi possível com a reabertura política, já que a prática foi utilizada sistematicamente pelos governos militares) (Corrêa, 2007; Trindade, 1994; Alves, 2003).

Outra diretriz inovadora da política externa foi a ênfase no processo de integração regional, com o início das negociações para a instituição do MERCOSUL (Corrêa, 2007). Como veremos nos governos posteriores, os migrantes e refugiados provenientes de países vizinhos também passaram a ter especial atenção.

No plano interno, o Brasil percorria o caminho rumo à reestruturação política, com o estabelecimento de novas instituições, como a elaboração da constituição de 1988. O texto incorporou a prevalência dos direitos humanos, a concessão de asilo político e a integração regional como princípios norteadores das relações internacionais (Brasil, 1988).

O período da redemocratização marcou uma nova fase na política brasileira para refugiados, recuperando o engajamento com o tema, assim como sua tradição humanitária, que havia se iniciado no pós-guerra, mas havia recuado durante a ditadura militar.

No pós-guerra, o Brasil teve uma atuação ativa em prol do tema dos refugiados. Participou da Conferência internacional em que se discutiu o texto preparatório da Convenção de 1951 e a assinou no ano seguinte à sua elaboração (embora adotando a reserva geográfica). Também foi eleito membro do Comitê Consultivo do ACNUR, dentre quinze Estados que haviam manifestado interesse e devoção à causa, ao acolher contingente significativo de refugiados. De fato, o Brasil recebeu cerca de 40 mil europeus em 1954. O Comitê Consultivo foi substituído pelo Comitê Executivo, do qual o Brasil faz parte até hoje (Zarjevski, 1987).

A ditadura militar, de 1964 a 1985, viria a alterar radicalmente a política brasileira para refugiados, marcando-se pelo retrocesso em relação ao período anterior, já que o Brasil deixava de ser país de acolhimento para se tornar país de 
origem de refugiados. Na então conjuntura política doméstica, não fazia sentido reconhecer como refugiados pessoas que fugiam de outros regimes ditatoriais na região, tampouco conceder-lhes abrigo. A justificativa dada pelo governo era jurídica (fundamentada na reserva geográfica), mas as motivações eram claramente políticas.

Em 1977, começaram os trabalhos da organização internacional e instituições da sociedade civil brasileira em prol dos refugiados, ligadas à Igreja Católica, a qual se engajou na luta pelo respeito aos direitos humanos em oposição ao regime militar no país (Carvalho, 2002). O ACNUR instalou seu escritório no Rio de Janeiro (o qual só foi reconhecido oficialmente pelo governo brasileiro em 1982), exercendo a função reassentar cerca de 20 mil sul-americanos em países desenvolvidos. A Cáritas Arquidiocesana do Rio de Janeiro iniciou o atendimento a refugiados, assistindo-os até que o ACNUR conseguisse um país de reassentamento (Almeida, 2001; Comissão Justiça e Paz, 1994; Sprandel e Milesi, 2003).

Em 1979, com a anistia concedida pelo governo Figueiredo (1979-1984), no processo de abertura política lenta, gradual e segura, exilados e refugiados políticos brasileiros retornaram ao país. Ao mesmo tempo, 150 vietnamitas e dezenas de cubanos foram assistidos pela Comissão de Justiça e Paz e pela Cáritas Arquidiocesana de São Paulo. Com isso, o Brasil deixava de ser país de origem e voltava a ser país de acolhimento de refugiados. No ano seguinte, foi aprovado o Estatuto do Estrangeiro (Lei n. 6815/80), que regulamentava a situação do imigrante no país a partir de considerações de "segurança nacional, organização institucional, interesses políticos, sócio-econômicos e culturais do Brasil e defesa do trabalhador nacional". Ainda estabeleceu uma esfera institucional própria: o Conselho Nacional de Imigração (CNIg), vinculado ao Ministério do Trabalho, com participação de representantes dos Ministérios da Justiça, das Relaçôes Exteriores, da Agricultura e da Saúde, com a função de orientar, coordenar e fiscalizar as atividades de imigração (Brasil, 1980). No último governo militar, a imigração foi tratada pela ótica securitária, a partir da noção de ameaça, perigo, inimigo da nação, que também orientava a confrontação bipolar entre as superpotências.

Ao mesmo tempo em que o Brasil voltou a receber refugiados, passou a ser também um país de emigração, em função da situação econômica (vale lembrar que a inflação e o endividamento externo marcaram a "década perdida"). Nos anos que se seguiram à redemocratização, entre 1985 e 1987, aproximadamente 1,2 milhão de pessoas deixaram o Brasil em busca de melhores oportunidades no exterior. Além disso, as remessas enviadas pelos emigrados passavam a adquirir peso econômico. Se o país passava a exportar nacionais para países desenvolvidos, a partir da reciprocidade internacional, precisava tratar bem os migrantes e refugiados que residiam aqui. Fazia-se necessário mudar o tratamento dado a esses grupos, não mais sob a ótica da segurança nacional, mas pela perspectiva humanitária (Barbosa e Sagrado da Hora, 2007). 
Alguns pontos merecem ser ressaltados com relação à política brasileira para refugiados nesse período. O país dá um passo importante ao retirar a reserva geográfica em 1989, passando a reconhecer refugiados de quaisquer origens (não mais apenas europeus). E também avança com a adesão ao regime regional para refugiados, ao aplicar a definição ampliada da Declaração de Cartagena de 1984. O número de refugiados acolhidos pelo país dá um salto significativo, passando de 322 para 1.042 pessoas (após o recebimento de 720 angolanos) em 1994. Nesse mesmo ano, estabeleceu-se formalmente o Centro de Acolhida para Refugiados pela Cáritas SP (Andrade, 1996; Almeida, 2001; Comissão Justiça e Paz, 1994).

Com a redemocratização, novos componentes domésticos aliados a fatores políticos externos propiciaram o posicionamento favorável ao tema dos refugiados. A questão entrou no debate nacional atrelada ao tema dos direitos humanos, em destaque na cena internacional. Isso se deveu não só a interesses defendidos pelo novo governo, mas também às instituiçôes religiosas que tiveram atuação importante na fase de transição do fim do regime militar e o percurso em prol da recuperação da democracia. Também foi relevante a participação da agência da ONU nesse processo.

\section{Governo FHC: avanços no fortalecimento do tema}

O governo Fernando Henrique Cardoso (1994-2002) teve uma atuação marcante em prol dos direitos humanos. Um dos elementos que contribuíram para tanto foi o fato de ter sido o presidente, em suas palavras, "pessoalmente perseguido pelas forças de repressão e forçado a deixar o país por alguns anos" (Cardoso: 2006, 549). O objetivo do governo era mudar a imagem internacional do país nessa área, diante das denúncias de violaçōes de direitos humanos no âmbito interno (Cardoso, 2006). A política externa do período se voltou para a participação em foros multilaterais em prol dos temas globais, adesão aos regimes internacionais e atuação frente às organizações internacionais, com a pretensão de se tornar membro permanente do Conselho de Segurança da ONU. Além disso, prezaram-se as relaçôes com países em desenvolvimento, priorizando-se os da América do Sul (em especial do MERCOSUL), sendo que as coalizóes para cooperação Sul-Sul ganharam destaque no segundo mandato. É interessante notar que, a partir dessas diretrizes, o Brasil procurou se projetar como global player, buscando ampliar sua participação no processo de formulação de regras dos regimes internacionais (Vigevani e Cepaluni, 2007; VIGEVANI, OLIVEIRA e et al, 2003).

A ênfase no tema também se fez notar no âmbito institucional doméstico, tornando-se política de governo, com a adoção do Programa Nacional de Direitos Humanos (PNDH I) em 1996 e a criação, no ano seguinte, da Secretaria de Direitos Humanos, vinculada ao Ministério da Justiça, para coordenar e monitorar a execução do plano. A formulação do programa, que enfatizava os direitos 
civis e políticos, contou com a participação de organizações internacionais e da sociedade civil brasileira. Além disso, seguia a recomendação da Conferência de Viena realizada três anos antes (Brasil, 1996; Pinheiro e Mesquita Neto, 1997).

Dentre as metas estabelecidas pelo primeiro PNDH, a elaboração de projeto de lei para regulamentar o estatuto dos refugiados foi tratada como proposta de ação governamental a ser executada em curto prazo (Brasil, 1996). A rápida aprovação do Projeto de Lei n. 1.936/96, formulado com a colaboração técnica do ACNUR, contou com o apoio da Comissão de Direitos Humanos da Câmara dos Deputados e foi fruto também da pressão exercida pela Igreja Católica, através das Cáritas (SP/RJ) e do Instituto de Migraçōes e Direitos Humanos (IMDH) (Andrade, 1996; Andrade e Marcolini, 2002a; Comissão Justiça e Paz, 1994). A participação da sociedade civil brasileira, através de suas mais diversas organizações, atuando em conjunto com o governo brasileiro, era considerada pelo presidente Cardoso (2006) elemento fundamental para a implementação das políticas públicas de direitos humanos.

\section{A legislação nacional}

A lei federal n. 9.474 de 1997 se insere nos marcos dos regimes internacional e regional para refugiados, incorporando os motivos clássicos de refúgio da Convenção de 1951 e os motivos ampliados da Declaração de Cartagena de 1984, sobretudo a violação de direitos humanos:

Artigo $1^{\circ}$ - Será reconhecido como refugiado todo individuo que:

I - devido a fundados temores de perseguição por motivos de raça, religião, nacionalidade, grupo social ou opiniōes políticas, encontre-se fora de seu país de nacionalidade e não possa ou não queira acolher-se à proteção de tal país;

(...)

III - devido à grave e generalizada violação de direitos humanos, é obrigado a deixar seu país de nacionalidade para buscar refúgio em outro país (Brasil, 1997).

A legislação brasileira é considerada avançada, moderna e inovadora, sobretudo por conta de sua definição abrangente de refugiado (Andrade e Marcolini, 2002b; ACNUR, 2005a, Leão, 2007). Outra inovação se refere ao direito de reunião familiar, estendendo-se a concessão do refúgio aos demais membros da família do refugiado. Nesse ponto, avançou-se em relação ao regime internacional da ONU, já que esse princípio havia sido consignado na Ata Final da Conferência, mas não no bojo da Convenção de 1951 (Moreira, 2004).

Em diversas questôes, seguiram-se as previsões da referida convenção, como as cláusulas de exclusão e cessação da condição de refugiado. As primeiras se referem às hipóteses de pessoas que não podem ser reconhecidas como refugiados, uma vez que já se beneficiam da proteção ou assistência da ONU, ou que não merecem ou 
não necessitam de tal proteção internacional. Já as segundas se verificam quando deixarem de existir as condiçóes que motivaram o refúgio ou quando o refugiado, por iniciativa própria, voltar a se valer de proteção estatal, seja de seu país de origem ou de outro Estado. Ademais, também foram adotados o princípio da não-devolução, impedindo que o refugiado seja devolvido para outro país em que haja risco de perseguição, e a não punição do refugiado devido à entrada irregular no território nacional. A lei pátria acrescentou a impossibilidade de extradição do refugiado com fundamento nos motivos do refúgio (Moreira, 2004; ACNUR, 1996; Brasil, 1997).

E, por fim, elencou as chamadas soluções duráveis para os refugiados, frisando o seu caráter voluntário: a integração local, em que o refugiado é recebido pelo país de destino e procura se integrar à sociedade acolhedora; o repatriamento, em que o refugiado é mandado de volta a seu país de origem, quando cessarem as condiçôes que ensejaram o refúgio; e o reassentamento, em que o refugiado, já reconhecido pelo primeiro país de asilo, é transferido para um terceiro país, por motivos de saúde, reunião familiar, dificuldades no processo de integração, dentre outros (Moreira, 2004; Barbosa e Sagrado da Hora, 2007).

O Brasil foi o primeiro país na América do Sul a elaborar uma legislação nacional específica na área, tendo sido também pioneiro na adesão ao regime internacional para os refugiados. Andrade e Marcolini (2002b) consideram que a lei brasileira possa se alçar a um modelo jurídico e legislativo, contribuindo para a harmonização de políticas e instrumentos legais de proteção aos refugiados no âmbito do processo de integração regional. Essa ideia se relaciona com a formulação da nova política imigratória nacional, já que a instituição encarregada, o CNIg defende uma política específica de admissão que beneficie trabalhadores sulamericanos. Recentemente, em outubro de 2008, o conselho aprovou a resolução normativa n. 80 , que facilita a autorização de trabalho para esses estrangeiros (CNIg, 2008b). No mesmo sentido, o decreto no 6.975/2009 regulamentou o acordo de residência para nacionais dos Estados que fazem parte do MERCOSUL, Bolívia e Chile (Brasil, 2009).

\section{Arena institucional e processo decisório}

A lei brasileira estabeleceu um órgão colegiado para julgar os pedidos de refúgio, decidindo quem seria reconhecido como refugiado no país, assim como os casos de perda e cessação do refúgio, e responsável por "orientar e coordenar as ações necessárias à eficácia da proteção, assistência e apoio jurídico aos refugiados” (Brasil, 1997). Não por acaso é presidido pelo Ministério da Justiça e vice-presidido pelo Ministério das Relações Exteriores, tendo em vista que os refugiados constituem um assunto humanitário e envolvem considerações tanto de política doméstica quanto de política externa. Também é formado por representantes dos Ministérios do Trabalho, da Saúde, da Educação e do Desporto, do Departamento da Polícia 
Federal e por um representante da sociedade civil. O ACNUR tem direito a voz, mas não a voto. Cabe ao Ministro da Justiça proferir a decisão final em matéria de refúgio.

O arranjo institucional do CONARE consolida a estrutura tripartite que já estava sendo montada desde meados de 1970 no Brasil, reunindo os principais atores em relação aos refugiados: instituições religiosas, que representam a sociedade civil brasileira (Cáritas e IMDH), organização internacional (ACNUR) e governo brasileiro (representado por seus órgãos burocráticos e presidindo o CONARE) (Leão, 2007). Esse desenho institucional, especialmente por incluir a participação da sociedade civil no processo decisório, também creditou à legislação de refúgio um caráter plural e democrático (Nogueira e Marques, 2008).

\section{Programa de reassentamento solidário}

A legislação nacional também havia previsto a implementação de programas de reassentamento para refugiados "de forma planificada e com a participação coordenada dos órgãos estatais e, quando possível, de organizações não-governamentais, identificando áreas de cooperação e de determinação de responsabilidades" (Brasil, 1997).

A partir de acordo com o ACNUR, em 1999, estabeleceu-se o Programa de Reassentamento Solidário, a fim de reinstalar refugiados que continuavam sofrendo ameaças ou efetivas perseguiçōes ou não conseguiam se adaptar ao primeiro país de refúgio (Dominguez e Baeninger, 2006). A organização internacional, que tem privilegiado ações em países de origem, da região e em desenvolvimento, havia escolhido o Brasil, dentre outros países, para ser novo centro de reassentamento de refugiados no mundo (Andrade e Marcolini, 2002a; Idem, 2002b).

A meta inicial do programa brasileiro era receber pequenos grupos, 30 refugiados seriam instalados em quatro cidades brasileiras (Porto Alegre/RS, Mogi das Cruzes/SP, Santa Maria Madalena/RJ e Natal/RN), totalizando 120 refugiados por ano. O projeto piloto, desenvolvido em pequena escala, era compatível com a capacidade de absorção socioeconômica local, sem sobrecarregar os serviços públicos nem afetar sobremaneira a sociedade receptora (Andrade e Marcolini, 2002a; Idem, 2002b).

O contexto internacional pós-11 de Setembro impulsionou a concretização do programa brasileiro de reassentamento. No discurso pronunciado na ONU em 2001, o presidente Fernando Henrique Cardoso declarou o seguinte: "o Brasil espera que, apesar de todas as circunstâncias, não se vejam frustradas as ações de ajuda humanitária ao povo do Afeganistão. Mais ainda: dentro de nossas possibilidades, estamos dispostos a abrigar refugiados que queiram integrar-se ao nosso país" (Corrêa, 2007, p. 682).

O pequeno grupo de 23 refugiados afegãos chegou no ano seguinte, com a coordenação do CONARE, financiamento do ACNUR, colaboração da 
Associação Antonio Vieira do Rio Grande do Sul e do Centro de Orientação e Encaminhamento de Porto Alegre (CENOE). Adotar um projeto piloto com refugiados de origem, cultura e tradição tão distintas das nossas representou um grande desafio. As maiores preocupações do governo brasileiro recaíram sobre a recepção dos refugiados pela população local e a consecução de um processo de inserção bem sucedido (Andrade e Marcolini, 2002b).

Com o governo FHC, houve avanços que propiciaram o fortalecimento do tema dos refugiados. Ao final do segundo mandato, em 2002, havia claramente se delineado uma política de governo para refugiados, aliada aos direitos humanos. Isso se observa pelo PNDH II, que enfocava os direitos econômicos, sociais e culturais, e estabelecia como meta de ação: "promover a capacitação das autoridades nacionais diretamente envolvidas na execução da política nacional para refugiados" (Brasil, 2002). Inaugurou-se uma política de reassentamento que coincidia com as diretrizes da política externa brasileira, voltadas para a defesa dos direitos humanos, atuação frente às organizações internacionais, solidariedade e cooperação com regimes internacionais e países em desenvolvimento.

\section{Governo Lula: rumo à consolidação do tema}

O governo de Luiz Inácio Lula da Silva (2003-) promoveu ajustes de programas em relação à política externa de seu antecessor, Fernando Henrique Cardoso, configurando uma "mudança na continuidade" nas palavras de Vigevani e Cepaluni (2007). Com isso, suas diretrizes mantiveram: o multilateralismo, a cooperação, a defesa dos direitos humanos, a adesão aos regimes e o respeito às organizações internacionais. Porém, enfatizaram a cooperação Sul-Sul e a aproximação com países em desenvolvimento e países africanos de língua portuguesa, com o escopo de obter vantagens políticas e econômicas. Acentuaramse as aspiraçōes em torno da reforma do Conselho de Segurança da ONU (empreendendo-se maiores esforços para tanto, a exemplo da missão brasileira enviada para a operação de paz no Haiti), do papel de destaque entre países em desenvolvimento. A liderança regional e a América do Sul se tornaram prioridades, levando o país a assumir a posição de administrador de crises e conflitos na região (Soares de Lima e Hirst, 2006).

\section{País emergente de reassentamento}

O tema dos refugiados, como já afirmado, tornou-se política governamental na administração de FHC e o governo Lula continuou investindo esforços nesse sentido. Da mesma forma, a política de reassentamento não só foi mantida, como incrementada, com ênfase no âmbito regional.

No ano de 2004, em reunião realizada na Cidade do México para celebrar os vinte anos da Declaração de Cartagena, elaborou-se o Plano de Ação do México. 
As propostas de soluções para os refugiados na esfera regional contemplaram: 1) o Programa de auto-suficiência e integração cidades solidárias, um estudo piloto na America Latina voltado para integração mais efetiva dos refugiados nos centros urbanos; 2) o Programa integral fronteiras solidárias, com o propósito de promover o desenvolvimento sócio-econômico, beneficiando simultaneamente pessoas que pedem proteção internacional e as comunidades locais; e, 3) por iniciativa brasileira, o Programa Regional de Reassentamento, com base na solidariedade internacional e compartilhamento de responsabilidades, para proteger os refugiados que fugiam de conflitos e perseguiçôes na região e, ao mesmo tempo, ajudar os países que acolhem grande contingente de colombianos (ACNUR, 2004).

O Brasil não possui cotas anuais pré-fixadas para reassentados e tampouco por nacionalidade e envia missóes aos países de primeiro refúgio (formadas por funcionários do CONARE), para avaliar a viabilidade dos refugiados serem instalados no território nacional. O CONARE tem privilegiado dois grupos vulneráveis de reassentados: refugiados sem proteção física ou legal e mulheres em risco (como chefes de família ou vítimas de violência) (Nogueira e Marques, 2008).

O programa regional de reassentamento já beneficiou cerca de 300 colombianos que se encontravam na Costa Rica e no Equador. Há uma forte preocupação regional com esse grupo, estimando-se que 20 mil colombianos estejam em situação de refúgio na Amazônia, nas fronteiras entre Brasil e Colômbia. O governo brasileiro, em parceria com o ACNUR, também tem se voltado para essa população, com base no programa 'fronteiras solidárias' (ACNUR, 2007).

No final de 2007, o Brasil recebeu quase 100 palestinos, provenientes do campo de refugiados Rweished situado na Jordânia, na fronteira com o Iraque, pelo programa de reassentamento solidário (ACNUR, 2009).

Nesse sentido, o Brasil vem se destacando pela sua atuação quanto aos refugiados, atingindo o posto de $12^{\circ}$ país que mais reassenta refugiados no mundo no ano de 2006. O ACNUR reconhece o comprometimento brasileiro com a proteção dos refugiados e entende ser exemplar o tratamento que lhes é dado no país, tanto em termos de legislação quanto dos esforços empregados para a integração (ACNUR, 2005). Nesse sentido, considera o processo de refúgio brasileiro um dos mais justos e democráticos do mundo, ao incluir a participação da sociedade civil (Nogueira e Marques, 2008).

Ainda o considera um líder regional nessa matéria, com capacidade de ajudar a prevenir a intensificação de conflitos na região que possam resultar em novos fluxos. A concepção de liderança regional se observa pelo fato de o país ter sediado em novembro de 2007 um encontro sobre reassentamento na América Latina, reunindo países como Noruega (tradicional e experiente país de reassentamento), Argentina, Chile, Paraguai e Uruguai (Nogueira e Marques, 2008; ACNUR, 2005b). Esses dados mostram que a relação do Brasil com a agência especializada da ONU vem se estreitando, o que atende especialmente ao seu objetivo de se tornar membro permanente no Conselho de Segurança. 
Além disso, a proposta do programa de reassentamento regional levava em conta que os fluxos de refugiados poderiam desestabilizar os países vizinhos, atendendo, portanto, a considerações de segurança regional. Também coincidia com outros interesses externos, sobretudo o papel de mediador de crises e conflitos no cenário político sul-americano e o papel de protagonista na região.

\section{Refugiados no Brasil}

Hoje, segundo estatística do CONARE, 4.131 refugiados de 72 nacionalidades vivem no Brasil, dos quais 3.745 são "espontâneos", que chegam ao país por si só, freqüentemente através de redes sociais, e 386 reassentados, oriundos de outros países de primeiro asilo, pelos programas de reassentamento, coordenados pelo CONARE com o apoio do ACNUR e outras organizações da sociedade civil. O maior grupo acolhido é de angolanos (1.687); em seguida, aparecem os colombianos (551) e congoleses (356) (CONARE, 2009).

\section{Processo de integração}

A integração local dos refugiados constitui um processo complexo que abrange aspectos socioeconômicos e culturais. Para que este processo tenha resultado positivo, é preciso que o refugiado seja plenamente inserido na sociedade, o que requer a obtenção de emprego e moradia, aprendizado da língua, utilização de serviços públicos, especialmente saúde e educação. Outro ponto fundamental se refere à construção de relações sociais com membros da comunidade local (Ager e Strang, 2008).

As iniciativas para a inserção dos refugiados são levadas a cabo preponderantemente pela sociedade civil, embora também haja participação do ACNUR e do governo brasileiro nesse processo (o que remete à estrutura tripartite). As Cáritas, funcionando como Centro de Acolhida para Refugiados, auxiliam solicitantes de refúgio, desde que chegam ao país até a decisão final sobre seus pedidos, e refugiados já reconhecidos. Atuando em três frentes, assistência, proteção e integração, a Cáritas desenvolveu parcerias com outras instituições (inclusive privadas, como a chamada "família" S: SESC, SENAC, SENAI), unindo a maior rede de apoio aos refugiados na America Latina, da qual participam cerca de 96 organizaçōes da sociedade civil (Sprandel e Milesi, 2003; Nogueira e Marques, 2008).

$\mathrm{O}$ processo de integração sócio-econômica e, muitas vezes, cultural dos refugiados abrigados no país ainda acarreta muitos desafios. Os maiores problemas se referem a emprego, moradia e, notadamente, discriminação. Recente pesquisa realizada pelo Nepo/ Unicamp, em parceria com ACNUR, Cáritas e Secretaria Especial de Direitos Humanos, baseada em entrevistas com refugiados residentes em São Paulo e Rio de Janeiro, revelou que as condições de trabalho e os níveis salariais foram avaliados como insatisfatórios. $\mathrm{O}$ acesso aos serviços 
públicos também é considerado precário, principalmente em termos de saúde e moradia. Outro ponto marcante é que apenas 2,8\% participavam de programa governamental (bolsa família). Quanto à discriminação, da população residente em São Paulo, 53,4\% se declararam insatisfeitos ou muito insatisfeitos nesse quesito (Baeninger, 2008; Baeninger, Dominguez et al, 2007; ACNUR, 2009). Frequentemente associados a "fugitivos", grande parte da população brasileira desconhece quem sejam os refugiados, o que acarreta maiores empecilhos para sua integração na sociedade e inserção no mercado de trabalho.

No caso dos reassentados, há uma assistência maior, já que o ACNUR e o governo brasileiro destinam verbas às Cáritas e seus parceiros, que provêem ajuda de subsistência, moradia e curso de português aos refugiados e os auxilia na busca de emprego. Porém, após dez anos de implementação do programa de reassentamento, os desafios permanecem, sobretudo em relação à auto-suficiência dos refugiados (Dominguez e Baeninger, 2006; Nogueira e Marques, 2008).

\section{Conclusão: conquistas e desafios}

No período de redemocratização do país, o compromisso com o tema dos refugiados foi retomado, empreendendo-se esforços para fortalecê-lo e consolidá-lo. Contribuíram para tanto o destaque dado ao tema dos direitos humanos, aliado à democracia, no cenário internacional, além das novas diretrizes de política externa, conjugadas com elementos políticos internos, em especial, a mobilização de instituições da sociedade civil, que influenciaram não só o processo de adoção, mas principalmente auxiliam na implementação da política para refugiados no Brasil.

A política nacional para refugiados foi claramente articulada a partir do reassentamento. Não por acaso, já que, através do programa, pode-se ter um controle maior dos refugiados que chegam ao país. Em primeiro lugar, eles já foram reconhecidos como refugiados pelo ACNUR ou pelo primeiro país de asilo; em segundo, são recebidos em pequenos grupos, em números administráveis, o que facilita a absorção local. A partir da busca de inserção como global player, ao cooperar com a agência da ONU e aderir aos regimes internacionais, o país pretende se projetar como solidário, generoso em matéria de direitos humanos. Desponta como país 'emergente' no cenário internacional não mais apenas no aspecto econômico, mas também em questóes políticas e humanitárias. Ao mesmo tempo, investindo nas 'fronteiras solidárias', fortalece sua posição de líder no cenário regional.

Por outro lado, é preciso questionar: ao privilegiar uma política de reassentamento, o Brasil estaria priorizando refugiados (reassentados em detrimento de "espontâneos"; ou ainda, os grupos mais vulneráveis dentro dos reassentados)? Isso nos leva a crer que esta política é seletiva e restrita, logicamente, aos interesses brasileiros externos e internos.

Nesse sentido, ao longo dos últimos dois governos, observam-se não só conquistas, mas também problemas na política para refugiados desenhada e 
colocada em prática no país. As conquistas são bastante significativas, uma vez que o tema foi incorporado na agenda política doméstica, surtindo importantes efeitos institucionais, com a elaboração de uma legislação nacional, a criação de uma arena institucional, a definição do processo decisório e a inclusão, com ativa participação, da sociedade civil como atores nesse processo. Além disso, houve um aumento na admissão de refugiados.

Por outro lado, emergiram problemas que precisam ser enfrentados. $\mathrm{O}$ mais marcante deles é a não participação dos refugiados no processo de formulação das políticas que lhe dizem respeito. Obviamente, para que uma política como esta tenha eficácia, é preciso trabalhar em conjunto com o grupo ao qual se destina. $\mathrm{O}$ segundo se refere às dificuldades no processo de integração local, que se traduzem em desafios gerados também pelo programa de reassentamento. Afinal, como receber refugiados sem criar as condiçōes indispensáveis para assegurar sua plena integração? Recentemente, um grupo de palestinos reassentados protestou em Brasília, em frente ao escritório do ACNUR, reivindicando novo reassentamento para outro país, alegando que não tiveram suas demandas atendidas, especialmente nas áreas de saúde, moradia e emprego (Folha de S. Paulo, 2008).

Os desafios que se colocam não são poucos, tampouco de fácil e rápida resolução. Eles exigem uma reflexão conjunta aprofundada. Procuramos, em breves linhas, lançar luz sobre eles, com algumas sugestôes que podem auxiliar a remediá-los. Com relação à esfera institucional, o CONARE precisará dar voz às demandas dos refugiados, criando um canal institucional para ouvir e conhecer as necessidades do grupo. Os refugiados não devem ser tratados de forma passiva (como objeto de política), mas como sujeitos ativos, que possam se engajar e que devem contribuir para o processo político. Uma iniciativa interessante foi levada a cabo pelo CNIg, que realizou um grupo de trabalho, reunindo trabalhadores bolivianos com outras instituiçôes, para identificar problemas vivenciados por esses imigrantes no país e buscar soluçōes em conjunto (CNIg, 2008a). Além disso, o CONARE precisa conferir mais transparência às suas atividades e aos dados referentes aos refugiados no país, para que a sociedade brasileira possa acompanhar e avaliar o seu desempenho institucional. Um dilema central será conseguir mais financiamento para executar projetos em prol do grupo, o que é fundamental não só para assistir os refugiados, mas também para garantir maior autonomia e fortalecimento institucional.

Quanto ao processo de integração local, também se faz necessário obter maiores recursos a fim de concretizar políticas específicas para os refugiados, que apresentam necessidades especiais, que precisam ser atendidas. Há acenos nesse sentido com a criação de novas instituições: o Comitê Estadual para Refugiados de São Paulo e o Comitê Paulista para Imigrantes e Refugiados (o último por proposta da Comissão Municipal de Direitos Humanos). Os órgãos conferem mais espaço para a participação da sociedade civil e prevêem, dentre seus objetivos, a formulação e implementação de políticas públicas para os grupos. 
Todavia, essa decisão coloca em debate a possibilidade de possíveis conflitos, disputas, atritos com a comunidade local. Tanto a inserção dos refugiados como beneficiários de programas de assistência (como o Bolsa Família ou o Fome Zero) quanto a criação de programas específicos podem suscitar reações hostis aos refugiados. Com o intuito de evitá-las, é imprescindível executar programas educativos e informativos destinados à conscientização sobre a condição do refugiado e sua situação no país. Outra frente é a adoção de programas que beneficiem tanto os refugiados quanto a população local. Aqui se destaca a iniciativa do ACNUR, em parceria com a ONG Ação Comunitária no Brasil, ao realizarem uma campanha de saúde na favela Complexo da Maré, RJ, voltada não só para os refugiados, mas também para os moradores. A ação coordenada, de caráter informativo e cultural, se baseou na apresentação de uma peça teatral encenada por jovens brasileiros e angolanos. Esse tipo de esforço é importante, porque aproxima a comunidade local do grupo, um elemento essencial para um processo de integração bem sucedido (ACNUR, 2008).

A política brasileira para refugiados precisa suprir suas deficiências (e remediar possíveis falhas), aprendendo a partir da experiência na última década, para ser mais efetiva, atendendo de forma mais eficiente às necessidades dos refugiados abrigados no país.

\section{Referências bibliográficas}

ACNUR. A situação dos refugiados no mundo: cinqüenta anos de ação humanitária. Almada: Triunfadora Artes Gráficas, 2000.

ACNUR e Ação Comunitária no Brasil lançam campanha Maré da Saúde no RJ, publicado em Acnur.org, [http://www.acnur.org/t3/portugues/noticias/noticia/acnur-eacao-comunitaria-do-brasil-lancam-campanha-mare-de-saude-no-rj/]. Disponibilidade: 18/11/2008.

- Declaração e Plano de Ação do México para fortalecer a proteção internacional dos refugiados na América Latina, publicado em Acnur.org, [http:// www.acnur.org/t3/portugues/ documentos/]. Disponibilidade: 28/12/2004.

2008 Global Trends: refugees, asylum-seekers, returnees, internally displaced and stateless persons, publicado em Unchr.org, [http://www.unhcr.org/cgi-bin/texis/vtx/search?page=sea rch\&docid $=4 \mathrm{a} 375 \mathrm{c} 426 \&$ query $=2008 \% 20$ global $\% 20$ refugee $\% 20$ trends $]$. Disponibilidade: 15/06/2009.

Guterres praises Brazilian efforts to integrate refugees, publicado em Unchr.org, [www. unhcr.org/43722e6a2.html]. Disponibilidade: 9/11/2005.

. Manual de procedimentos e critérios a aplicar para determinar o estatuto de refugiado. Lisboa: ACNUR, 1996.

AGER, Alastair; STRANG, Alison. Understanding integration: a conceptual framework. Journal of Refugee Studies, Vol. 21, No 2, 2008, p. 166-191.

ALMEIDA, Guilherme Assis de. Direitos humanos e não-violência. São Paulo: Atlas, 2001. 
ALVES, José Augusto L. Os direitos humanos como tema global. São Paulo: Perspectiva, 2003.

ANDRADE, José Henrique Fischel de. O Brasil e a proteção de refugiados: a discussão tem início no Congresso Nacional. Pensando o Brasil: reflexôes e sugestôes para os problemas do Brasil, ano V, No 16, 1996, p. 7-12.

e MARCOLINI, Adriana. A política brasileira de proteção e de reassentamento de refugiados - breves comentários sobre suas principais características. Revista Brasileira de Politica Internacional, Vol. 45, No 1, 2002a, p. 168-176.

e __. Brazil's Refugee Act: model refugee law for Latin America? Forced Migration Review, No 12, 2002b, p. 37-39.

BRASIL. Constituição da República Federativa do Brasil. São Paulo: Atlas, 1988.

Decreto $n^{\circ}$ 6.975, de 7 de outubro de 2009, publicado em Planalto.gov.br, [http://www.planalto.gov.br/ccivil_03/_Ato2007-2010/2009/Decreto/D6975.htm]. Disponibilidade: 12/10/2009.

Lei no 6.815, de 19 de agosto de 1980, publicado em Planalto.gov.br, [http://www. planalto.gov.br/CCIVIL/LEIS/L6815.htm]. Disponibilidade: 12/06/2009.

Lei no 9.474, de 22 de julho 1997, publicado em ACNUR.org, [http://www.acnur.org/ t3/portugues/documentos/?tx_danpdocumentdirs_pi2[mode] =1\&tx_danpdocumentdirs_ pi2[folder]=66]. Disponibilidade: 12/06/2009.

Programa Nacional de Direitos Humanos I, publicado em Planalto.gov.br, [http://www. planalto.gov.br/publi_04/COLECAO/PRODH1.HTM]. Disponibilidade: 13/05/1996.

Programa Nacional de Direitos Humanos II, publicado em Planalto.gov.br, [http://www.planalto.gov.br/publi_04/COLECAO/PRODH2.HTM]. Disponibilidade: 28/12/2002.

BAENINGER, Rosana (Coord.). População Refugiada: retrato das condições de vida das famílias em São Paulo e Rio de Janeiro. Campinas: Nepo/ Unicamp, 2008.

; DOMINGUEZ, Juliana e AYDOS, Mariana. Condições de Vida da População Refugiada: divulgação da pesquisa de campo e resultados preliminares. Anais do V Encontro Nacional de Migraçôes. Campinas, Nepo/ Unicamp, 2007.

BARBOSA, Luciano P. e SAGRADO DA HORA, José R. A policia federal e a proteção internacional dos refugiados. Brasília: ACNUR, 2007.

CARDOSO, Fernando H. A Arte da Política: a história que vivi. Rio de Janeiro: Civilização Brasileira, 2006.

CARVALHO, José Murilo de. Cidadania no Brasil: o longo caminho. Rio de Janeiro: Civilização Brasileira, 2002.

CNIg. Bolivianos, paraguaios e chilenos apresentam proposta para o Grupo de Trabalho do MTE, publicado em MTE.gov.br, [http://www.mte.gov.br/sgcnoticia.asp?IdConteudoNoticia=26 46\&PalavraChave=grupotrabalho tem]. Disponibilidade: 31/03/2008.

Resolução Normativa $N^{o} 80,16$ de outubro de 2008, publicado em MTE.gov.br, [http://www.mte.gov.br/legislacao/resolucoes_normativas/2008/rn_20081016_80.pdf]. Disponibilidade: 26/10/2008.

COMISSÃO JUSTIÇA E PAZ. Direitos Humanos no Brasil: 1992-1993. São Paulo: Loyola, 1994.

CONARE. Refúgio, publicado em MJ.gov.br, 
[http://www.mj.gov.br/data/Pages/MJ7605B707ITEMIDE5FFE0F98F5B4D22AFE703 E02BE2D8EAPTBRIE.htm]. Disponibilidade: 16/06/2009.

CONLEY, Marshall. The institutional framework of refugee law and political forces. In: MAHONEY, Kathleen; MAHONEY, Paul (Ed.) Human Rights in twenty-first century: a global challenge. Dordrecht: Kluwer Academic Publications, 1993.

CORRÊA, Luiz Felipe de Seixas (Org.). O Brasil nas Naçôes Unidas: 1946-2006. Brasília: FUNAG, 2007.

DECLARAÇÃO DE CARTAGENA. In: ARAUJO, Nadia; ALMEIDA, Guilherme Assis de (Coord.). O Direito Internacional dos Refugiados: uma perspectiva brasileira. Rio de Janeiro: Renovar, 2001.

DOMINGUEZ, Juliana A.; BAENINGER, Rosana. Programa de reassentamento de refugiados no Brasil. Anais da Associação Brasileira de Estudos Populacionais. Caxambu, 2006.

FOLHA DE S. PAULO. Palestinos acampados em Brasilia querem deixar o país, publicado em Folha.com.br, [http://www1.folha.uol.com.br/folha/mundo/ult94u415157.shtml]. Disponibilidade: 23/06/2008.

HOLLIFIELD, James. The Politics of International Migration: how can we "bring the State back in"? In: BRETTELL, Caroline; (Ed.). Migration Theory: talking across disciplines. New York: Routledge 2000. p. 137-175.

JACOBSEN, Karen. Factors influencing the policy responses of host governments to mass refugee influxes. International Migration Review, Vol. 30, N 3, 1996, p. 655-678.

LEĀO, Renato Zerbini R. (Comp.). O reconhecimento dos refugiados pelo Brasil: decisóes comentadas do CONARE. Brasília: CONARE; ACNUR, 2007.

LOESCHER, Gil. The UNHCR and world politics: state interests vs. institutional autonomy. International Migration Review, Vol. 35, No 1, 2001, p. 33-56.

MATAS, David. A history of the politics of refugee protection. In: MAHONEY, Kathleen; Mahoney, Paul. (Ed.). Human Rights in the Twenty-First Century: a global challenge. Dordrecht: Kluwer Academic Publishers, 1993. p. 619-628.

MEYERS, Eytan. Theories of International Immigration Policy: a Comparative Analysis. International Migration Review, Vol. 34, No 4, 2000, p. 1.245-1.282.

MOREIRA, Julia B. A proteção internacional aos refugiados e a legislação brasileira (Lei Federal 9.747/97). In: Estudos de Direito Internacional-Anais do $2^{\circ}$ Congresso Brasileiro de Direito Internacional. vol. II. Curitiba: Juruá, 2004.

NOGUEIRA, Maria B. e MARQUES, Carla C. Brazil: ten years of refugee protection. Forced Migration Review, No 30, 2008, p. 57-58.

SOARES DE LIMA, Maria R. e HIRST, Mônica. Brazil as an intermediate state and regional power: action, choice and responsibilities. International Affairs, Vol. 82, No 1, 2006, p. 21-40.

SPRANDEL, Márcia A. e MILESI, Rosita. O acolhimento a refugiados no Brasil: histórico, dados e reflexões. In: MILESI, Rosita (Org.). Refugiados: realidade e perspectivas. Brasília: CSEM/IMDH; Loyola, 2003.

TRINDADE, Antonio Augusto C. A proteção internacional dos direitos humanos no limiar do novo século e as perspectivas brasileiras. In: FONSECA JR, Gelson; CASTRO, Sergio Henrique Nabuco de (Org.). Temas de política externa brasileira II. Brasília: FUNAG, 1994. p. 167-187. 
UNRWA. Statistics, publicado em UN.org, [http://www.un.org/unrwa/publications/index. html]. Disponibilidade: 15/06/2009.

VIGEVANI, Tullo e CEPALUNI, Gabriel. A política externa de Lula da Silva: a estratégia da autonomia pela diversificação. Contexto internacional, Vol. 29, No 2, 2007, p. 273-335.

; OLIVEIRA, Marcelo F. e CINTRA, Rodrigo. Política externa no período FHC: a busca de autonomia pela integração. Tempo Social, ano 15, No 2, 2003, p. 31-61.

ZARJEVSKI, Yéfime. A Future Preserved: international assistance to refugees. Oxford: Pergamon Press, 1987.

Recebido em 4 de agosto de 2009 Aprovado em 14 de janeiro de 2010

\section{Resumo}

O presente trabalho analisa a política para refugiados no Brasil dos anos 1990 aos dias atuais. Diante do contexto internacional marcado pelos novos temas globais, dentre os quais direitos humanos e migrações forçadas, e do processo de redemocratização no plano doméstico, o tema dos refugiados foi tratado no país, atrelado aos direitos humanos.

\section{Abstract}

This article analyses the refugee policy of Brazil from the 1990's until today. It considers the international context marked by the new themes of the global agenda (such as human rights, forced migration and the re-democratization process in the domestic scenery) and links the refugee issue to human rights.

Palavras chave: refugiados; redemocratização brasileira; direitos humanos.

Key-words: refugees; Brazilian re-democratization; human rights. 